\title{
Erratum to: Long-range corrected DFT calculations of charge-transfer integrals in model metal-free phthalocyanine complexes
}

\author{
Mikołaj M. Mikołajczyk • Robert Zaleśny • \\ Żaneta Czyżnikowska • Petr Toman • \\ Jerzy Leszczynski • Wojciech Bartkowiak
}

Published online: 15 April 2011

(C) Springer-Verlag 2011

\section{Erratum to: J Mol Model}

DOI 10.1007/s00894-010-0865-7

The original version of this article unfortunately contained a mistake. The fifth to thirteenth line below Equation 11 at page 6 should be:

For the intermolecular distance $3.5 \AA$, the rotation angle 0 and lateral slide $1.5 \AA$ (this is the structure similar to the crystal structure of the phthalocyanine) the charge-transfer integrals calculated with B3LYP and CAMB3LYP functional are $\mathbf{- 0 . 0 4 6} \mathrm{eV}$ and $\mathbf{- 0 . 0 5 3} \mathrm{eV}$ respectively. The charge carrier mobility values calculated from Eq. 11 for this two charge-transfer integrals are $0.32 \mathrm{~cm}^{2} / \mathrm{Vs}$ and $0.43 \mathrm{~cm}^{2} / \mathrm{Vs}$.

The online version of the original article can be found at http://dx.doi. org/10.1007/s00894-010-0865-7.

M. M. Mikołajczyk • R. Zaleśny • Ż. Czyżnikowska •

W. Bartkowiak ( $\square)$

Theoretical Chemistry Group, Institute of Physical and

Theoretical Chemistry, Wroclaw University of Technology,

Wybrzeże Wyspiańskiego 27,

50-370, Wrocław, Poland

e-mail: wojciech.bartkowiak@pwr.wroc.pl

\section{P. Toman}

Institute of Macromolecular Chemistry,

Academy of Sciences of the Czech Republic,

v.v.i., Heyrovský Sq. 2,

162 06, Prague 6, Czech Republic

Ż. Czyżnikowska

Department of Inorganic Chemistry, Faculty of Pharmacy,

Wroclaw Medical University,

Szewska 38,

50-139, Wrocław, Poland

R. Zaleśny $\cdot$ J. Leszczynski

Interdisciplinary Center for Nanotoxicity,

Department of Chemistry, Jackson State University,

Jr Lynch St. 1400,

Jackson, MS 39217, USA 